\title{
Age estimation based on pictures and videos presumably showing child or youth pornography_reply to Arlan L. Rosenbloom
}

\author{
F. Mayer • T. Arent • G. Geserick • C. Grundmann • \\ U. Lockemann • T. Riepert • A. Schmeling • \\ St. Ritz-Timme
}

Received: 15 September 2014 / Accepted: 16 September 2014 / Published online: 12 October 2014

(C) Springer-Verlag Berlin Heidelberg 2014

Arlan L Rosenbloom criticized that the recommendations published by Mayer et al. would be "daunting" because there would be "no data to support the validity of our approach". The characteristics listed in the recommendations would "serve to illustrate the subjectivity or impracticability of this effort" [1].

To a certain extent, we agree with Mr. Rosenbloom and want to emphasize once more, as we already did in the recommendations [2], that age estimation based only on pictures or videos is difficult and, in certain cases, even impossible. The assumption, however, that only expert advices, containing an "exact age diagnosis" of a depicted person are of use in criminal procedures is not completely true in many cases of forensic practise. In such cases, even a rough estimation of age may be very useful as long the expert outlines the limits of age estimation based on pictures or videos very clearly.

F. Mayer $(\bowtie) \cdot T$. Arent $\cdot S$. Ritz-Timme

Institute for Legal Medicine, University Hospital Düsseldorf,

Moorenstr. 5, 40225 Düsseldorf, Germany

e-mail: felix.mayer@med.uni-duesseldorf.de

G. Geserick

Berlin, Germany

C. Grundmann

Public health department, Ruhrorter Str. 195, 47166 Duisburg, Germany

U. Lockemann

Institute for Legal Medicine, Butenfeld 34, 22529 Hamburg,

Germany

T. Riepert

Institute for Legal Medicine, Am Pulverturm 3, 55131 Mainz, Germany

A. Schmeling

Institute for Legal Medicine, Röntgenstr. 23, 48149 Münster,

Germany
This might account for many cases, but it is also important to keep in mind that pornographic material exists in which the visible characteristics of a depicted person strongly implicate an age under or over the relevant age limits (e.g. as $\mathrm{Mr}$. Rosenbloom himself mentioned, prepubescent children). In such cases, the recommendations should help the medical expert to outline why it is scientifically justified to come to this assumption and which limitations still remain.

The recommendations mainly aim on harmonizing the delivered advices. The recommendations cannot and are not intended to solve the general methodological difficulties of age estimation based on pictures or videos. Delivering an experts' advice in cases of suspected child or youth pornography remains a challenging task and should only be done by experienced experts.

To avoid "disappointment" on the part of the patrons, we recommend again to explain the possibilities and the limitations of expert advices concerning age estimation in cases of suspected child or youth pornography before an order is accepted. Practical experience has shown that knowledge of the limitations does not automatically repel patrons. There is still a demand for scientific-based expert reports and their results, even if they do not include a precise age, are valued in criminal proceedings. Even if the crucial question cannot be answered by medical experts, such an advice might help to prevent medical laypersons from making hasty decisions.

\section{References}

1. Rosenbloom AL (2014) Subject: age estimation based on pictures and videos presumably showing child or youth pornography

2. Mayer F, Arent T, Geserick G, Grundmann C, Lockemann U, Riepert T, Schmeling A, Ritz-Timme S (2014) Age estimation based on pictures and videos presumably showing child or youth pornography. Int J Legal Med 128:649-652 